\title{
Blood-feeding, susceptibility to infection with Schmallenberg virus and phylogenetics of Culicoides (Diptera: Ceratopogonidae) from the United Kingdom
}

James Barber ${ }^{1 \dagger}$, Lara E. Harrup ${ }^{1 \dagger}$, Rhiannon Silk ${ }^{1}$, Eva Veronesi ${ }^{1,2}$, Simon Gubbins ${ }^{1}$, Katarzyna Bachanek-Bankowska ${ }^{1}$ and Simon Carpenter ${ }^{1 *}$

\begin{abstract}
Background: Culicoides biting midges (Diptera: Ceratopogonidae) are responsible for the biological transmission of internationally important arboviruses of livestock. In 2011, a novel Orthobunyavirus was discovered in northern Europe causing congenital malformations and abortions in ruminants. From field studies, Culicoides were implicated in the transmission of this virus which was subsequently named Schmallenberg virus (SBV), but to date no assessment of susceptibility to infection of field populations under standardised laboratory conditions has been carried out. We assessed the influence of membrane type (chick skin, collagen, Parafilm $\mathrm{M}^{\oplus}$ ) when offered in conjunction with an artificial blood-feeding system (Hemotek, UK) on field-collected Culicoides blood-feeding rates. Susceptibility to infection with SBV following blood-feeding on an SBV-blood suspension provided via either (i) the Hemotek system or via (ii) a saturated cotton wool pledglet was then compared. Schmallenberg virus susceptibility was defined by RT-qPCR of RNA extractions of head homogenates and related to Culicoides species and haplotype identifications based on the DNA barcode region of the mitochondrial cytochrome c oxidase 1 (cox1) gene.
\end{abstract}

Results: Culicoides blood-feeding rates were low across all membrane types tested (7.5\% chick skin, 0.0\% for collagen, 4.4\% Parafilm M${ }^{\oplus}$, with 6029 female Culicoides being offered a blood meal in total). Susceptibility to infection with SBV through membrane blood-feeding (8 of 109 individuals tested) and pledglet blood-feeding (1 of 94 individuals tested) was demonstrated for the Obsoletus complex, with both C. obsoletus (Meigen) and C. scoticus Downes \& Kettle susceptible to infection with SBV through oral feeding. Potential evidence of cryptic species within UK populations was found for the Obsoletus complex in phylogenetic analyses of cox1 DNA barcodes of 74 individuals assessed from a single field-site.

Conclusions: Methods described in this study provide the means to blood-feed Palaearctic Culicoides for vector competence studies and colonisation attempts. Susceptibility to SBV infection was 7.3\% for membrane-fed members of the subgenus Avaritia and 1.1\% for pledglet-fed. Both C. obsoletus and C. scoticus were confirmed as being susceptible to infection with SBV, with potential evidence of cryptic species within UK Obsoletus complex specimens, however the implications of cryptic diversity in the Obsoletus complex on arbovirus transmission remains unknown.

Keywords: Vector competence, Biting midges, Arbovirus, SBV, Orthobunyavirus, DNA barcode, cox1

\footnotetext{
* Correspondence: simon.carpenter@pirbright.ac.uk;

simon.carpenter@pirbright.ac.uk

${ }^{\dagger}$ Equal contributors

'Vector-borne Viral Disease Programme, The Pirbright Institute, Pirbright,

Surrey, UK

Full list of author information is available at the end of the article
} 


\section{Background}

In 2011, a novel Orthobunyavirus, provisionally named Schmallenberg virus (SBV), was discovered in Germany and was subsequently found to cause foetal abnormalities and abortions in ruminants [1-3]. To date, no convincing route for the incursion of SBV into Europe has been provided, echoing the outbreak of bluetongue virus (BTV) serotype 8 that occurred in the same region 5 years prior to this event [4]. Subsequently, surveys based upon detection of SBV antibodies, viral RNA and clinical disease in livestock demonstrated that the virus spread rapidly across the northwestern region of Europe during 2011-2012 [5-8]. Countries in the region then reported significant reductions in additional clinical cases and seroconversion to SBV infection during 2013-2014 [5, 9], driven by a lack of naïve hosts. Since these studies, recirculation of the virus in northwestern Europe has occurred [10], but the majority of monitoring surveys have been scaled back following reductions in clinical cases of disease and the deployment of an effective vaccine [11].

Culicoides biting midges (Diptera: Ceratopogonidae) were suspected as the primary biological vectors of SBV prior to direct study of transmission in the field, due to their involvement in the BTV epidemic in northwestern Europe 5 years earlier [12], and the close phylogenetic relationship of SBV with other Culicoides-borne orthobunyaviruses $[1,13]$. This hypothesis was confirmed by a series of field-based trials in Belgium, the Netherlands and France that detected significant quantities of SBV RNA in Culicoides collected in close proximity to livestock [14-18], while failing to detect virus in mosquitoes [19]. Techniques to assess the probability of field transmission of SBV by Culicoides and mosquitoes were standardised using colony lines of Culicoides sonorensis Wirth \& Jones and Culicoides nubeculosus (Meigen) infected using artificial membrane-based techniques [20, 21].

Within northwestern Europe, the Culicoides fauna on farms and stables are dominated by species classified within the subgenus Avaritia [18, 22, 23]. Until recently four species within this subgenus have been identified within this region and are commonly referred to as the Obsoletus group, despite a lack of monophyly: Culicoides obsoletus (Meigen) and Culicoides scoticus Downes \& Kettle; Culicoides dewulfi Goetghebuer and Culicoides chiopterus (Meigen) [24-26]. Several additional cryptic species have also recently been proposed whose taxonomic status, prevalence, abundance and involvement in transmission of arboviruses remains uncertain [27-29]. To date, these cryptic species have not been identified in the UK, despite a study that examined 79 individuals of the subgenus Avaritia using a $472 \mathrm{bp}$ region of the mitochondrial cytochrome $c$ oxidase subunit 1 gene (cox1) across ten geographically disparate sampling points [25].
All four established members of Culicoides (Avaritia) in northwestern Europe have been implicated in transmission of SBV. Schmallenberg virus RNA has been detected in homogenates of heads removed from field-collected $C$. obsoletus, C. scoticus and C. chiopterus individuals in the Netherlands [15], and additionally within heads of $C$. dewulfi collected in Belgium [17]. A key research limitation, however, is that techniques have not been developed to artificially blood-feed field-collected species of Palaearctic Culicoides through membranes under conditions of biological containment [30, 31]. This not only limits studies attempting to standardise population susceptibility to infection across the region, but also prevents the establishment of colony and cell lines of these species as a resource [32].

In this study we examined methods of blood-feeding species of field-collected Culicoides in the UK to provide a standard for comparative studies of vector competence across Europe. We then examined vector competence in a single population of Culicoides collected at a stable in Surrey, UK. To our knowledge, for the first time, we link standard detection of disseminated infections with haplotype-based identification based on Sanger-sequencing of the DNA barcode region of the mitochondrial cytochrome $c$ oxidase subunit 1 ( $\operatorname{cox} 1)$ gene. This not only provides preliminary data concerning susceptibility rates to SBV infection in known vector species of Culicoides in northwestern Europe, but also provides additional data concerning the complement of species and $\operatorname{cox} 1$ haplotypes that are present in the UK, with consequences for epidemiological studies of arbovirus transmission and epidemiology.

\section{Methods}

\section{Study site and collections}

Specimens of Culicoides were collected at a site in close proximity to horses at a stable in Surrey $\left(51^{\circ} 28.97 \mathrm{~N} ;-06^{\circ}\right.$ 52.03W) during 2012 and 2013 using two $8 \mathrm{~W}$ ultraviolet Onderstepoort Veterinary Institute (OVI) light-suction traps (Agricultural Research Council - Onderstepoort Veterinary Institute, Pretoria, South Africa) [33]. Collections were made overnight in a $500 \mathrm{ml}$ plastic beaker partially filled with damp paper hand-towel in an attempt to minimise the effects of desiccation on collected Culicoides. Following collection, collected insects were allowed to emerge from the beaker against a glass plane in front of natural daylight allowing selected aspiration of free-flying Culicoides for use during later experiments. These were transferred to netted, cylindrical, card $64 \mathrm{~mm}$ diameter pillboxes (Watkins and Doncaster, Stainton, UK) for use in later experiments.

\section{Effect of membrane type on blood-feeding rates}

All blood-feeding studies were conducted in 2012 using an artificial feeding system (Hemotek), with each feeder 
unit calibrated to warm the blood-meal to $37{ }^{\circ} \mathrm{C}$. Prior to being offered a blood-meal, all Culicoides were incubated for $96 \mathrm{~h}$ following collection, at $25 \pm 1{ }^{\circ} \mathrm{C}$ and $\geq$ $50 \%$ relative humidity $(\mathrm{RH})$ with ad libitum access to $10 \%(w / v)$ sucrose solution (Sigma-Aldrich, Gillingham, UK) provided via a saturated cotton wool pledglet placed on the netted tops of pillboxes. Pledglets were removed $24 \mathrm{~h}$ prior to offering Culicoides a blood meal. Three membrane types were compared, used in conjunction with an artificial feeding system (Hemotek). Blood-meal reservoirs containing approximately $3 \mathrm{ml}$ of defibrinated equine blood (TCS Biosciences, Botolph Claydon, UK) were covered with either a (i) stretched skins taken from one-day old-chicks; (ii) collagen membrane (Hemotek); or (iii) stretched Parafilm $\mathrm{M}^{\bullet}$ membrane (Bemis Company Inc., Neenah, WI, USA). Each membrane type was assessed in duplicate for each round of blood-feeding with membrane types randomly allocated two of the six feeders units per blood-feeding round. A total of nine days of duplicate replicates were completed for each membrane type. Blood meals were offered for a total of $45 \mathrm{~min}$, after which the contents of the pillboxes were killed via prolonged exposure to cold and Culicoides were identified to species or subgenus level according to their morphology with reference of appropriate keys [24]. In addition specimens were classified according to abdominal pigmentation (unpigmented or pigmented); blood-fed or gravid in the case of females [34, 35], or as males. Blood-feeding success rates were calculated using only unpigmented, pigmented and blood-fed females. The effect of membrane type and date of blood-feeding on the number of blood-fed Culicoides was assessed using a KruskalWallis test. Where the Kruskal-Wallis test was significant $(P<0.05)$, differences between factor levels were explored using pairwise Wilcoxon rank-sum tests.

\section{Vector competence}

All vector competence studies were conducted in August-October 2013. The SBV strain used for studies of infection was provided by IZS Teramo from an isolation originally made by the Friedrich-Loeffler-Institute, Isle of Riems, Germany [1]. This SBV strain had been passaged once through a $C$. sonorensis derived cell line and four times through a baby hamster kidney (BHK-21) cell line and then adjusted to a titre of $10^{6}$ tissue culture infectious dose $50\left(\mathrm{TCID}_{50}\right)$ using defibrinated equine blood (TCS Bioscience). All blood-feeding and sorting of Culicoides were carried out in a biosecure glove-box. Blood-virus mixes were offered using either (i) an artificial feeding system (Hemotek) as described above with a stretched Parafilm $\mathrm{M}^{\bullet}$ membrane (Bemis Company Inc.), or via (ii) a saturated cotton wool pledglet placed directly on top of the net of the pillboxes [31].

Blood meals were offered for a total of $45 \mathrm{~min}$, after which blood-fed Culicoides were selected under light $\mathrm{CO}_{2}$ anaesthesia and then incubated in netted, cylindrical, card $64 \mathrm{~mm}$ diameter pillboxes (Watkins and Doncaster) for eight days at $25^{\circ} \mathrm{C}$ with ad libitum access to $10 \%(w / v)$ sucrose solution (Sigma-Aldrich) provided via a cotton wool pledglet placed on top of the netted pillboxes. Culicoides surviving the incubation period were then selected under $\mathrm{CO}_{2}$ anaesthesia and transferred to $1.5 \mathrm{ml}$ Eppendorf tubes containing 70\% ethanol and stored at $4{ }^{\circ} \mathrm{C}$ prior to further analysis.

Specimens were individually removed from storage in $70 \%$ ethanol and decapitated using a sterile needle (Monoject $^{\mathrm{Tu}}$ hypodermic needle, $18 \mathrm{~g} \times 1.5$; Covidien, Minneapolis, MN, USA). Heads were then transferred individually to $1.5 \mathrm{ml}$ microcentrifuge tubes containing 100 $\mu \mathrm{l}$ Schneider's Drosophila Media (Gibco ${ }^{\mathrm{rw}}$, Paisley, UK) and homogenised using disposable polypropylene pestles (Sigma-Aldrich). The remaining abdomen and thorax of

Table 1 Comparison of membrane type with an artificial feeding system (Hemotek, UK) on Culicoides blood-feeding rate (blood-feeding rate with range and total number offered a blood meal shown in parentheses). Data exclude gravid females and males exposed to blood-feeding system

\begin{tabular}{llll}
\hline Culicoides spp./ Species complex & \multicolumn{2}{l}{ Blood-feeding rate (\%) } & Parafilm M $\mathbf{M}^{\oplus}$ \\
\cline { 2 - 4 } & Chick skin & $0(n=1331)$ & $5.0(0-32.0 ; n=1555)$ \\
\hline Obsoletus complex $(n=4270)$ & $8.0(0-16.0 ; n=1384)$ & $0(n=50)$ & $0(n=44)$ \\
C. dewulfi Goetghebuer $(n=121)$ & $7.0(0-33.0, n=27)$ & - & $0(n=1)$ \\
C. chiopterus (Meigen) $(n=2)$ & - & - & - \\
C. pulicaris (L.) $(n=34)$ & $0.03(0-33.0 ; n=34)$ & $0(n=19)$ & $0.10(0-100.0 ; n=29)$ \\
C. punctatus (Meigen) $(n=85)$ & $0(n=37)$ & $0(n=2)$ & $0(n=1)$ \\
C. impunctatus Goetghebuer $(n=4)$ & $0(n=1)$ & $0(n=87)$ & $2.0(0-25.0 ; n=83)$ \\
C. achrayi (Kettle \& Lawson) $(n=255)$ & $8.0(0-33.0 ; n=85)$ & $0(n=6)$ & $0(n=24)$ \\
C. festivipennis Kieffer $(n=43)$ & $30.8(0-100.0 ; n=13)$ & - & - \\
Other Culicoides spp. $(n=4)$ & $0(n=4)$ & $0(0)$ & $76(4.3)$ \\
Total blood-fed $(\%)$ & $119(7.9)$ & & \\
\hline
\end{tabular}


Table 2 Susceptibility to infection with Schmallenberg virus for Culicoides (Avaritia) collected at a single site in the UK

\begin{tabular}{lll}
\hline Subgenus Avaritia & \multicolumn{2}{l}{ Feeding method } \\
\cline { 2 - 3 } & Membrane $^{\mathrm{a}}$ & Pledglet $^{\mathrm{a}}$ \\
\hline & $109(13)$ & $94(2)$ \\
C. pulicaris (L.) & $2(2)$ & $4(0)$ \\
C. punctatus (Meigen) & $4(0)$ & $6(0)$ \\
C. achrayi (Kettle \& Lawson) & $23(0)$ & - \\
C. festivipennis Kieffer & $9(0)$ & - \\
Total & $147(15)$ & $104(2)$
\end{tabular}

$a_{n}$ with total with a quantification cycle $\left(C_{q}\right) \leq 40$ in parenthesis

each individual was transferred to a collection microtube (Qiagen, Manchester, UK) containing $100 \mu \mathrm{l}$ of Schneider's Drosophila Media and a $3 \mathrm{~mm}$ stainless steel bead (Dejay Distribution Ltd., Launceston, UK) and homogenised for $1 \mathrm{~min}$ at $25 \mathrm{hz}$ using a TissueLyser (Qiagen).

\section{Schmallenberg virus detection}

Total nucleic acid was extracted from the homogenates of Culicoides heads using a Universal Biorobot (Qiagen) with a QIAamp All Nucleic Acid MDx Kit (Qiagen) following the manufacturer's recommended instructions. Schmallenberg virus RNA in the resultant extractions was the assessed using a semi-quantitative RT-qPCR targeting the $S$ segment of the genome $[1,20]$. A $C_{q}$ cut-off value of $<35$ was used to define SBV infection [15].

\section{cox1 DNA barcode assay}

Amplification of a $658 \mathrm{bp}$ fragment of the DNA barcoding region of the mitochondrial $\operatorname{cox} 1$ gene [36] was achieved by polymerase chain reaction (PCR). Reactions were performed in a total volume of $25 \mu \mathrm{l}$ consisting of $13.65 \mu \mathrm{l}$ nuclease-free water (Qiagen), $2.5 \mu \mathrm{l} 10 \times$ PCR Buffer (Life Technologies, Paisley, UK), $0.75 \mu \mathrm{l} 50 \mathrm{mM} \mathrm{MgCl}$ (Life Technologies), $0.5 \mu \mathrm{l} 10 \mathrm{mM}$ dNTP mix (Life Technologies); $0.1 \mu \mathrm{l}$ Platinum ${ }^{\circ}$ Taq DNA polymerase (Life Technologies), $1.25 \mu \mathrm{l}$ of the $20 \mu \mathrm{M}$ forward primer, $1.25 \mu \mathrm{l}$ of the $20 \mu \mathrm{M}$ reverse primer and $5.0 \mu \mathrm{l}$ of template DNA (approximately 5-25 ng DNA) per reaction. Amplification of the DNA barcode region was initially attempted using the following primer pair: LCO1490 (5'-GTC AAC AAA TCA TAA AGA TAT TGG-3' [37]) and HCO2198 (5'TAA ACT TCA GGG TGA CCA AAA AAT CA-3' [37]). If the DNA barcode region could not be sucessfully amplified using primers LCO1490 and HCO2198, the above assay was repeated using the following alternative primer pair: LepF1 (5'-ATT CAA CCA ATC ATA AAG ATA TTG G-3' [38]) and LepR1 (5'-TAA ACT TCT GGA

Table 3 Observed quantification cycle $\left(C_{q}\right)$ values for Schmallenberg virus (SBV) in field-collected Culicoides. Includes associated Culicoides species characterisation and blood-feeding method (- indicates no sequence data available; Obsoletus complex includes C. obsoletus (Meigen) and C. scoticus Downes \& Kettle)

\begin{tabular}{|c|c|c|c|c|c|c|}
\hline \multirow[t]{2}{*}{ Species } & \multirow[t]{2}{*}{$\mathrm{BIN} \mathrm{N}^{\mathrm{a}}$} & \multirow[t]{2}{*}{ Blood-feeding method } & \multirow[t]{2}{*}{ SBV $C_{q}$ value } & \multicolumn{3}{|c|}{ Culicoides DNA barcode } \\
\hline & & & & Sample ID & GenBank ID & BOLD process ID \\
\hline \multirow[t]{10}{*}{ C. obsoletus (Meigen) } & \multirow[t]{9}{*}{ BOLD:AAO7718 } & Membrane & 32.95 & TPI:ENT:\#0000313 & KT186817 & CUSBV066-15 \\
\hline & & Membrane & 32.84 & TPI:ENT:\#0000314 & KT186816 & CUSBV067-15 \\
\hline & & Membrane & 33.64 & TPI:ENT:\#0000315 & KT186815 & CUSBV068-15 \\
\hline & & Membrane & 31.00 & TPI:ENT:\#0000316 & KT186814 & CUSBV069-15 \\
\hline & & Membrane & 37.88 & TPI:ENT:\#0000319 & KT186813 & CUSBV072-15 \\
\hline & & Membrane & 37.44 & TPI:ENT:\#0000320 & KT186812 & CUSBV073-15 \\
\hline & & Membrane & 36.11 & TPI:ENT:\#0000321 & KT186860 & CUSBV074-15 \\
\hline & & Membrane & 38.10 & TPI:ENT:\#0000322 & KT186859 & CUSBV075-15 \\
\hline & & Membrane & 32.61 & TPI:ENT:\#0000323 & KT186858 & CUSBV076-15 \\
\hline & BOLD:AAM6198 & Membrane & 31.92 & TPI:ENT:\#0000325 & KT186863 & CUSBV078-15 \\
\hline \multirow[t]{2}{*}{ C. scoticus Downes \& Kettle } & \multirow[t]{2}{*}{ BOLD:AAZ3985 } & Pledglet & 37.88 & TPI:ENT:\#0000317 & KT186880 & CUSBV070-15 \\
\hline & & Pledglet & 33.83 & TPI:ENT:\#0000318 & KT186881 & CUSBV071-15 \\
\hline \multirow[t]{3}{*}{ Obsoletus complex } & - & Membrane & 34.00 & - & - & - \\
\hline & - & Membrane & 27.12 & - & - & - \\
\hline & - & Membrane & 37.67 & - & - & - \\
\hline \multirow[t]{2}{*}{ C. pulicaris (L.) $)^{\mathrm{b}}$} & - & Membrane & 28.17 & - & - & - \\
\hline & - & Membrane & 35.95 & - & - & - \\
\hline
\end{tabular}

Barcode Index Numbers (BINs) [49] assigned within the Barcode of Life Database (BOLD) [39] for specimens collected within this study: specimens TPI:ENT:\#0000248-TPI:ENT:\#0000262; TPI:ENT:\#0000264-TPI:ENT:\#0000283; TPI:ENT:\#0000285-TPI:ENT:\#0000286; TPI:ENT:\#0000288-TPI:ENT:\#0000312 [GenBank: KT186808-KT186811; KT186818-KT186857; KT186861-KT186862; KT186864-KT186879]

${ }^{\mathrm{b}}$ Species identification based on morphology only 
TGT CCA AAA AAT CA-3' [38]). Positive and negative controls for the amplification reactions were carried out at every PCR round. The PCR cycling conditions for all DNA Barcode assays were as follows: an initial denaturation step at $94{ }^{\circ} \mathrm{C}$ for $2 \mathrm{~min}$ followed by 35 cycles of $94{ }^{\circ} \mathrm{C}$ for $30 \mathrm{~s}$, $46{ }^{\circ} \mathrm{C}$ for $30 \mathrm{~s}, 72{ }^{\circ} \mathrm{C}$ for $1 \mathrm{~min}$, and a final extension step at $72^{\circ} \mathrm{C}$ for $10 \mathrm{~min}$. PCR products were visualised using ultraviolet light and $2 \%$ agarose gels containing SYBR $^{\circ}$ Safe DNA Gel Stain (Invitrogen, Paisley, UK). Successful amplification of the cox 1 DNA barcode region was indicated by the presence of a band at approximately $720 \mathrm{bp}$ for both primer pair LCO1490 and HCO2198 and primer pair LepF1 and LepR1, identified by comparison with E-Gel ${ }^{\circ}$ Low Range Quantitative DNA Ladder (100-2000 bp; Life Technologies).

\section{PCR purification and cox 1 sequencing}

Dimer formation from the primers was not observed and purification of the remaining PCR product was performed using a GFX ${ }^{\mathrm{TM}}$ PCR DNA and Gel Band Purification Kit (GE Healthcare Life Sciences, Little Chalfont, UK), following the manufacturer's recommended guidelines. The amplicons were sequenced bi-directionally using BigDye Terminator v3.1 Cycle Sequencing kit (Applied Biosystems, Paisley, UK) in a 3730 DNA Analyzer (Applied Biosystems) according to the manufacturer's instructions using the primer pairs as per the PCR amplification either HCO2198 and LCO1490, or LepF1 and LepR1.

\section{Phylogenetic analysis}

Electropherograms were edited and forward and reverse sequences assembled and trimmed to remove primer sequence using CodonCode Aligner v. 5.1.5 (CodonCode Aligner, Centerville, MA, USA). Corresponding specimen collection data and DNA sequences including electropherograms have been made publically available via the Barcode of Life Data System (BOLD) [39] as dataset DS-CUSBV (dx.doi.org/10.5883/DS-CUSBV), DNA sequences were also submitted to the GenBank database (accession numbers KT186808-KT186881).

Consensus sequences were compared to previously published sequences in GenBank using the standard nucleotide BLAST tool [40], in addition to comparison to as yet unreleased sequence data in the BOLD database [39] using the Barcode Identification Engine in BOLD v3. Obsoletus group cox1 sequences which overlapped the DNA barcode region [36] by at least $390 \mathrm{bp}$ were obtained from both BOLD $(n=25)$ and GenBank $(n=393)$ and included in the phylogenetic analysis (Additional file 1: Table S1), these sequences were selected in order to assess if the haplotypes identified within this study were concordant with those identified from other geographical regions.
All sequences were aligned using MUSCLE [41] and the alignment quality checked using GUIDANCE [42] (100 bootstraps). All included sequences were aligned with a high degree of confidence (GUIDANCE alignment score $>0.999)$. jModelTest $[43,44]$ v. 2.1 .7 was then used to determine the most suitable DNA substitution model among the 24 models that can be implemented in MrBayes [45, 46]. The model with the lowest Bayesian information criterion (BIC) and Akaike information criterion (AIC), the Hasegawa-Kishino-Yano with gamma-distribution rates $(\mathrm{HKY}+\mathrm{G})$ [47], was considered to best describe the nucleotide substitution pattern.

The phylogenetic relationships among taxa were resolved using a Bayesian inference (BI) approach using the $\mathrm{HKY}+\mathrm{G}$ nucleotide substitution model rooted on the partial cox1 sequence of C. imicola Kieffer (GenBank: KT307824) [48]. The BI tree was constructed using MrBayes v. 3.2.2 [46, 49] and twenty million tree generations in four chains were run, sampling every 1000 th and discarding the first $25 \%$, before constructing a $50 \%$ majority rule consensus tree reporting Bayesian posterior probabilities. Convergence was assessed using

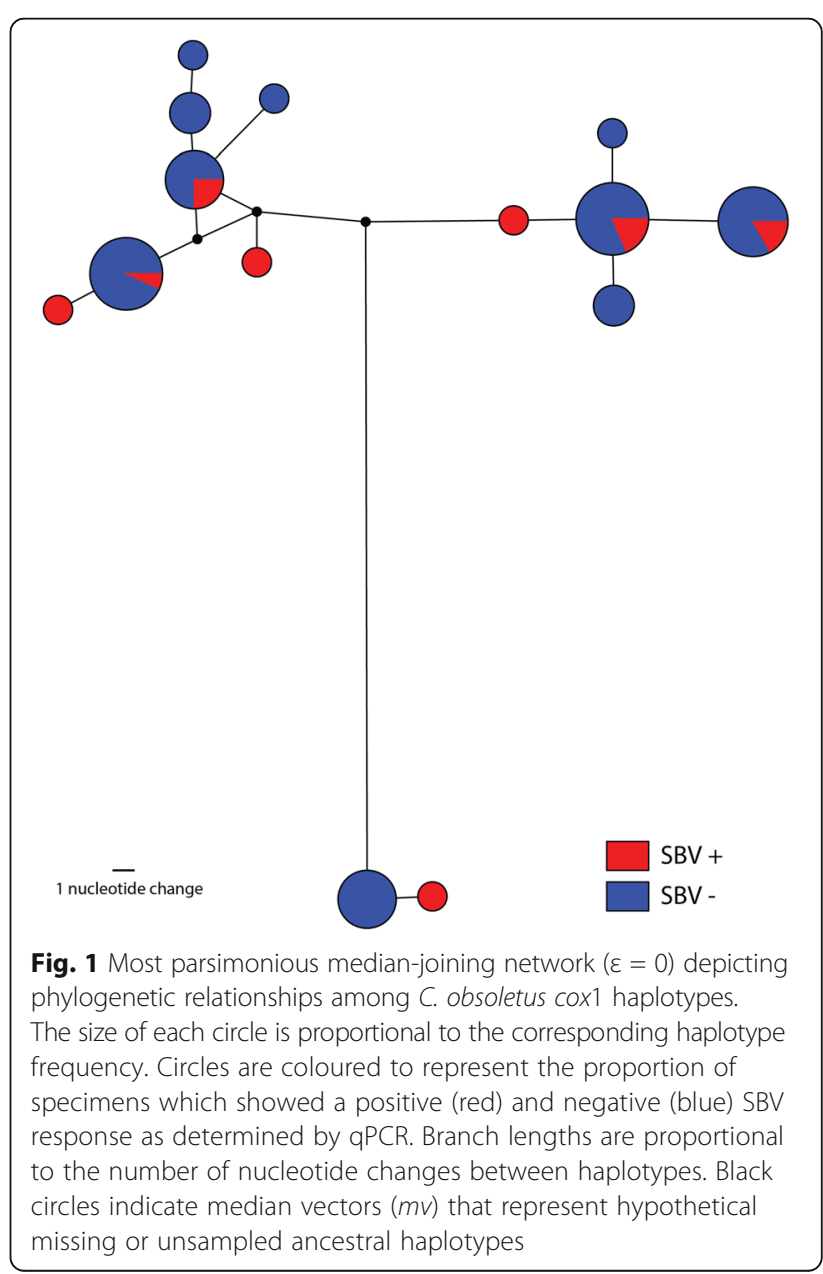


AWTY [50]. The BI trees were visualised using the packages Ape v. 3.2 [51] and Phytools v. 0.4-60 [52] implemented in R v. 3.1.2 [53].

Relationships between the observed haplotypes within the C. obsoletus specimens for which SBV vector competence data were available $(n=67)$ (GenBank: KT186812-KT186878), were assessed by constructing Median-Joining networks. Roehl haplotype data files (RDF) were created with DnaSP v5.10 [54] and imported into Network v4.6.1.2 [55]. Networks were calculated with the Median-Joining algorithm [56] with equal weights for all characters, using maximum parsimony [57] post-processing. Intra- and inter-specific uncorrected percent nucleotide sequence distances, were generated using the packages Spider v. 1.3-0 [58] and Ape v. 3.2 [51] implemented in R v. 3.1.2 [53]. Missing nucleotides were treated in all sequence comparisons using a pairwise deletion option.

\section{Results}

\section{Effect of membrane type on blood-feeding}

A total of 6029 Culicoides were used in the experiments to investigate the effect of membrane type on Culicoides blood-feeding rates: 4681 specimens of the Obsoletus complex including the morphologically cryptic C. obsoletus (Meigen) and C. scoticus Downes \& Kettle; 157 C. dewulfi; 4. C. chiopterus; 127 C. pulicaris (L.); 138 C. punctatus (Meigen), 4 C. impunctatus Goetghebuer; 321 C. achrayi
Kettle \& Lawson; 537 C. festivipennis Kieffer; 60 individuals from other Culicoides species (Additional file 2: Table S2). Excluding gravid females and males, a total of 4270 specimens of the Obsoletus complex; 121 C. dewulfi; 2 C. chiopterus; 96 C. pulicaris; 85 C. punctatus; 4 C. impunctatus; 255 C. achrayi; 43 C. festivipennis were exposed to the membrane systems during trials (Table 1). Only bloodfeeding rates of the species of the Obsoletus complex provided sufficient sample sizes for further statistical analysis. Membrane type had a significant (Kruskal-Wallis test: $X^{2}=27.1, d f=2, P<0.0001$ ) effect on Obsoletus complex Culicoides blood-feeding rate, with both chick skin (Wilcoxon rank-sum test: $W=27, P<0.0001$ ) and Parafilm $\mathrm{M}^{\bullet}$ (Wilcoxon rank-sum test: $W=297, P<0.0001$ ) membrane resulting in a significantly higher bloodfeeding rate that the collagen membrane. There was no significant (Wilcoxon rank-sum test: $W=180, P=0.57$ ) difference in blood-feeding rate between Obsoletus complex Culicoides fed via chick skin and Parafilm $\mathrm{M}^{\circ}$ membrane. The day of blood-feeding also had no significant effect (Kruskal-Wallis test: $\chi^{2}=2.7, d f=7, P=0.91$ ) on blood-feeding rates.

\section{Vector competence}

In total, 147 Culicoides survived the eight day incubation period post-feeding on the blood-virus mix through an artificial membrane; of these 13 (11.9\%) of Culicoides (Avaritia)

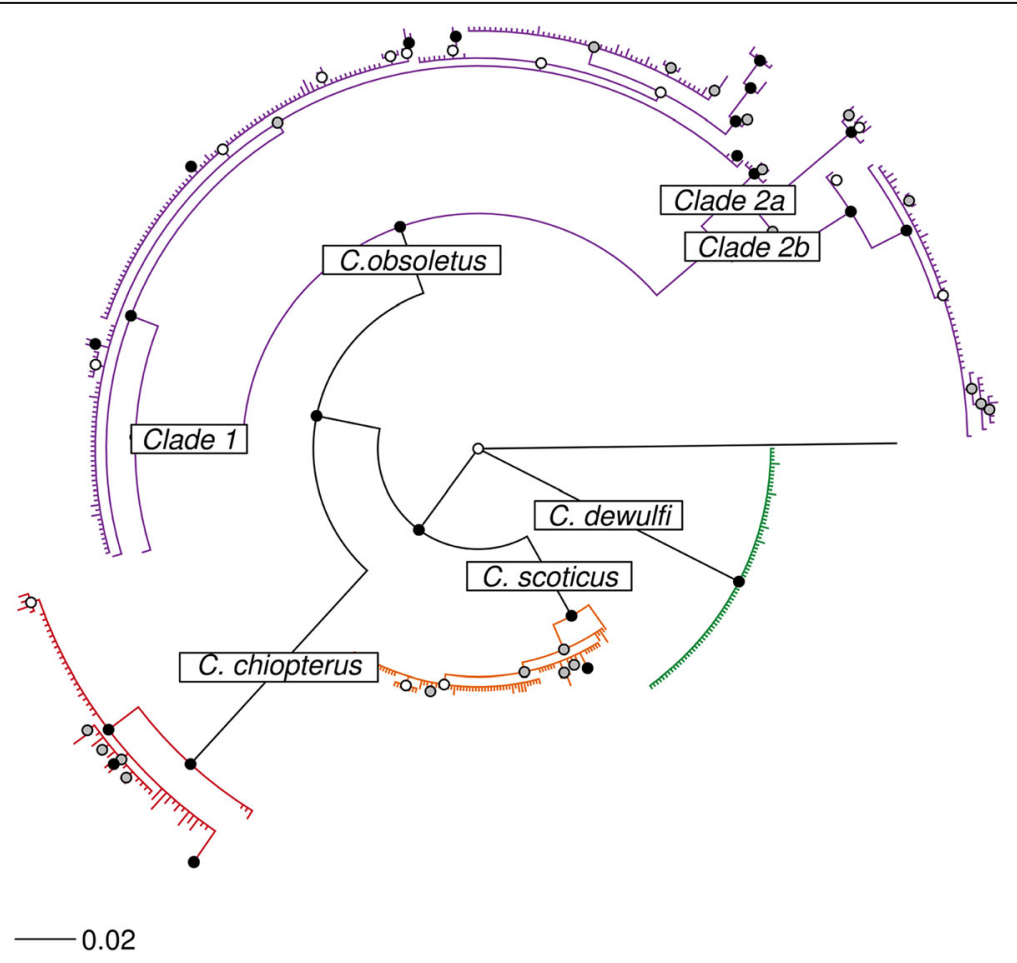

Fig. 2 Simplified Bayesian inference phylogenetic tree inferred from cox1 DNA barcode sequences with species assignments indicated. Bayesian posterior probability node support values $\geq 0.95$ are shown as solid black circles at nodes, $0.75-0.94$ shown as black outline circles with grey fill at nodes and $<0.75$ shown as black outline circles with white fill at nodes 
contained significant quantities of SBV RNA within their heads $\left(C_{q} \leq 40\right)$ (Table 2). Using a more conservative cutoff level for detection of SBV RNA $\left(C_{\mathrm{q}} \leq 35\right)$, this number fell to $8(7.3 \%)$. In total, 104 Culicoides were successfully fed using pledglet blood-feeding, of which 94 were from the subgenus Avaritia (Table 2). Of these, 2 (2.1\%) contained significant quantities of SBV RNA in their heads $\left(C_{q} \leq 40\right)$ (Tables 2,3). Using a more conservative cut-off level for detection of SBV RNA $\left(\mathrm{C}_{\mathrm{q}} \leq 35\right)$, this number fell to $1(1.1 \%)$. In $C$. pulicaris fed using a membrane method both processed individuals tested positive for disseminated SBV RNA of which one had a $C_{q}$ value lower than the conservative cut-off (Table 3). Heads from no other species examined contained detectable levels of SBV RNA (Table 2).

\section{Phylogenetic analysis}

Full length primer truncated (658 bp) DNA barcode sequences $(n=74)$ were obtained from three species of the subgenus Avaritia: C. obsoletus $(n=67), C$. scoticus $(n=3)$ and $C$. dewulfi $(n=4)$. No insertions, deletions, amino acid frame shifts or stop codons were observed among these sequences, and their translations, indicating that pseudogenes were not present within the alignments. DNA barcodes were obtained from 12 of a total of 15 specimens containing SBV RNA in their heads $\left(C_{\mathrm{q}}\right.$ $\leq 40$ ): ten from membrane-fed individuals and two from pledglet-fed individuals (Table 3). Ten were identified as C. obsoletus (Table 3), there was, however, no apparent association between haplotype and SBV vector competence within this species (Fig. 1). DNA from a further three specimens could not be amplified successfully and these were identified on the basis of morphology only as belonging to the Obsoletus complex (Table 3). DNA barcodes for an additional 46 membrane-fed Culicoides and 17 pledglet-fed Culicoides lacking detectable SBV RNA $\left(C_{\mathrm{q}} \geq 40\right)$ were also generated and analysed (Table 3).

Phylogenetic analysis of the DNA barcodes from specimens generated within this study together with cox 1 sequences obtained from GenBank and

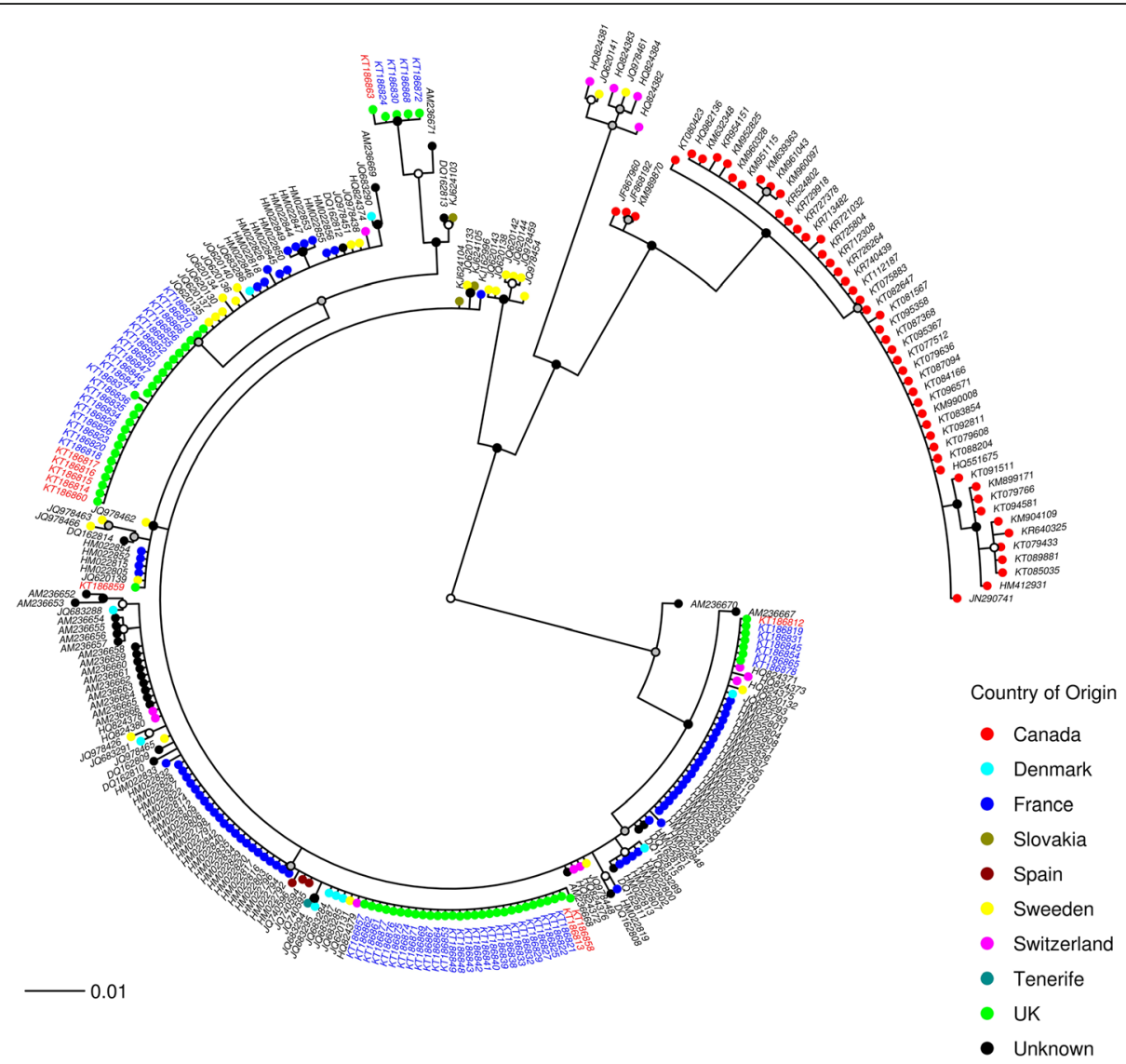

Fig. 3 Bayesian inference phylogenetic tree inferred from C. obsoletus cox1 DNA barcode sequences. Bayesian posterior probability node support values $\geq 0.95$ are shown as solid black circles at nodes, 0.75-0.94 shown as black outline circles with grey fill at nodes and $<0.75$ shown as black outline circles with white fill at nodes. Geographical origin of specimens indicated by a coloured circle preceding the GenBank accession number for the sequence. Schmallenberg virus (SBV) vector competence indicates by colour of the GenBank accession number tip labels (red, positive; blue, negative; black, unknown). Clades shown represented in purple in Fig. 2 


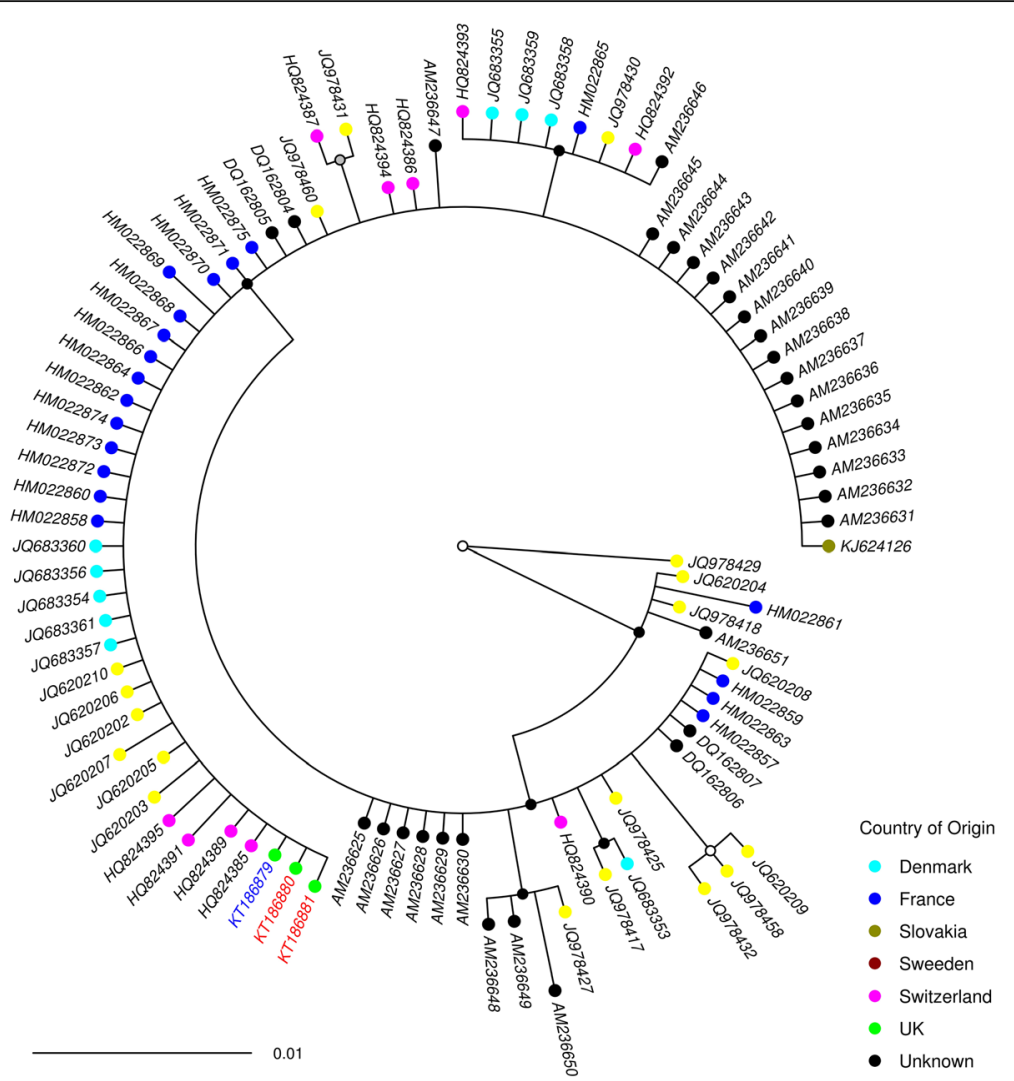

Fig. 4 Bayesian inference phylogenetic tree inferred from C. scoticus cox 1 DNA barcode sequences. Bayesian posterior probability node support values $\geq$ 0.95 are shown as solid black circles at nodes, $0.75-0.94$ shown as black outline circles with grey fill at nodes and $<0.75$ shown as black outline circles with white fill at nodes. Geographical origin of specimens indicated by a coloured circle preceding the GenBank accession number for the sequence. Schmallenberg virus (SBV) vector competence indicates by colour of the GenBank accession number tip labels (red, positive; blue, negative; black, unknown). Clades shown represented in orange in Fig. 2

BOLD (Additional file 1: Table S1) indicated that the species clades represented in the BI phylogeny were concordant with morphological identifications generated using the key of Campbell \& Pelham-Clinton [24] (Figs. 2, 3, 4, 5, 6). The cox1 sequences obtained from GenBank and BOLD overlapped the $658 \mathrm{bp}$ DNA barcodes generated in this study by between $391 \mathrm{bp}$ and $658 \mathrm{bp}$.

Deep interspecific differences within the cox 1 DNA barcode region were present between the majority of Culicoides species present within the phylogenetic analysis (Table 4, Figs. 2, 7; Additional file 1: Figures S1, S2). The greatest intraspecific nucleotide sequence difference was between $C$. dewulfi and C. chiopterus [mean 22.5\% (range: 20.5-23.5\%)], while the least was between $C$. obsoletus and C. scoticus [mean 12.2\% (range: 10.914.3\%)] (Table 4; Additional file 1: Figure S2). Sequence differences symptomatic of cryptic species diversity were, however, present within C. obsoletus (Table 4; Additional file 1: Figure S2). Intraspecific nucleotide sequence differences were observed between specimens nominally identified as C. obsoletus ranging from 0 to $12.3 \%$.
Barcode Index Number (BINs) [49] assigned within BOLD [39] for C. scoticus (BOLD:AAZ3985, $n=3$ ) and C. dewulfi (BOLD:AAZ3991, $n=4$ ) were concordant across all specimens sequenced within this study, however discordant BINs were observed for the C. obsoletus specimens sequenced within this study (Concordant BINs exhibit $>2 \%$ nucleotide sequence divergence [49]). This resulted in two BINs (BOLD:AAM6198, $n=5$; BOLD:AA07718, $n=62$ ) being assigned for specimens putatively identified as $C$. obsoletus thereby indicating the potential presence of two distinct taxa (see Table 3, dataset DS-CUSBV: dx.doi.org/10.5883/DS-CUSBV).

\section{Discussion}

This study has developed artificial blood-feeding techniques for Culicoides in the UK and then demonstrated susceptibility to infection with SBV in multiple haplotypes of C. obsoletus and C. scoticus under laboratory conditions. The results confirm those that identified SBV RNA in the heads of these species in close proximity to ruminants in the Netherlands [15], Belgium [17] 


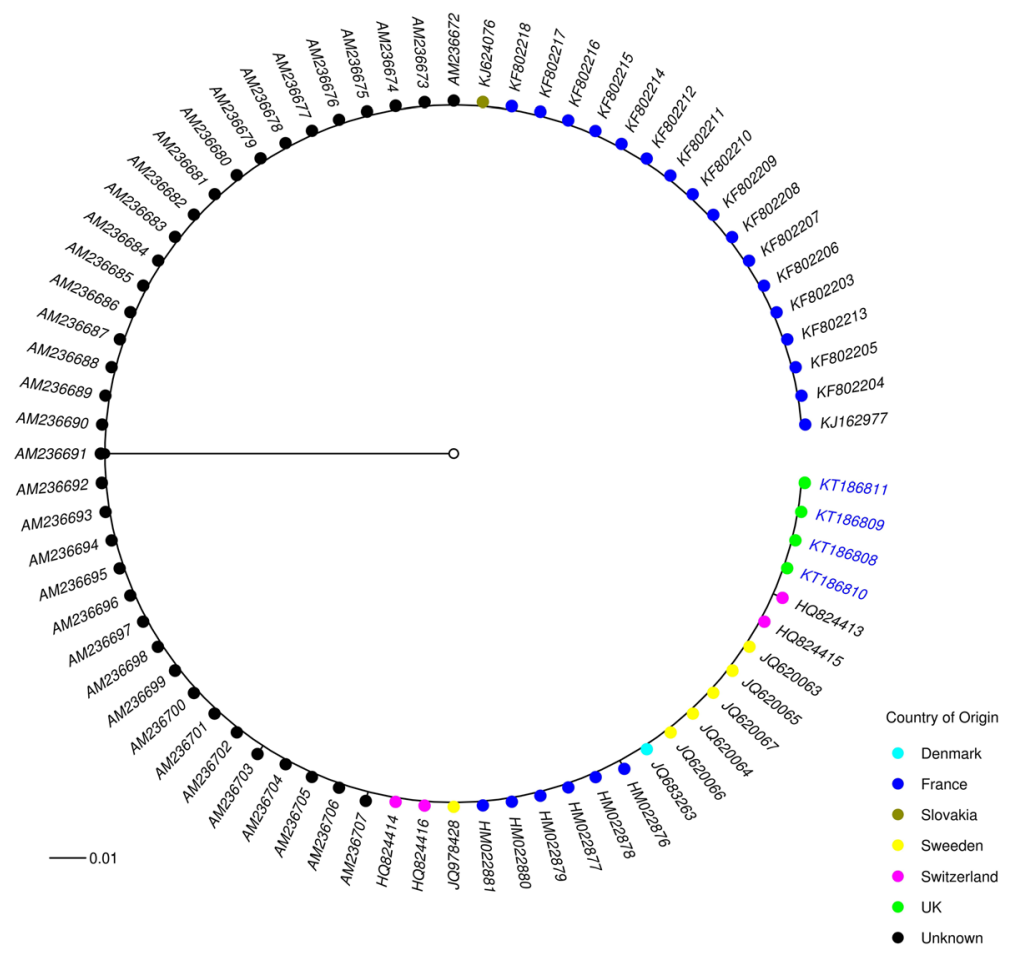

Fig. 5 Bayesian inference phylogenetic tree inferred from C. dewulfi cox1 DNA barcode sequences. Bayesian posterior probability node support values $\geq 0.95$ are shown as solid black circles at nodes, $0.75-0.94$ shown as black outline circles with grey fill at nodes and $<0.75$ shown as black outline circles with white fill at nodes. Geographical origin of specimens indicated by a coloured circle preceding the GenBank accession number for the sequence. Schmallenberg virus (SBV) vector competence indicates by colour of the GenBank accession number tip labels (red, positive; blue, negative; black, unknown). Clade shown represented in green in Fig. 2

and France [14]. Blood-feeding of Culicoides on pledglets was also demonstrated to underestimate rates of susceptibility to infection, as found previously with BTV $[30,31]$. The sequencing of the DNA barcode region (658 bp) of the cox 1 gene for 67 individuals putatively identified as $C$. obsoletus from a single site in the UK provides potential evidence of cryptic diversity, however, how this relates to the morphologically cryptic species previously described in the Netherlands, Sweden and Switzerland [27-29,59] remains unclear.

Blood-feeding techniques developed within this study enabled the first membrane-based artificial feeding experiments using northwestern European Culicoides since the 1980s [60]. Unlike the original method, which relied upon the use of populations in close proximity to contained facilities, the technique had the advantage of including an incubation step that precluded the inclusion of naturally blood-fed individuals from traps and can be used with light-suction trap collections from a wide geographical area. While blood-feeding rates remained poor, this development is useful in creating a platform for both vector competence experimentation and wider vectorvirus interaction studies in addition to laboratory-based studies of bionomics for which little data is available for the subgenus Avaritia in northwestern Europe [32].
Further investigation of techniques to improve feeding rates is now required as provided for $C$. impunctatus in northwestern Europe [61, 62].

A high rate of vector competence for SBV in Culicoides is hypothesised to be at least partly responsible for driving the rapid geographic spread of the virus in Europe $[14,15,63]$. While the preliminary data provided in the current study shows that susceptibility to infection with SBV is low, significant variation in vector susceptibility to infection according to population tested has been documented for Culicoides of the subgenus Avaritia in the UK for BTV [30]. Hence, further screening of Culicoides populations utilising multiple populations across Europe would be beneficial in improving our understanding of transmission and in informing mathematical modelling studies $[63,64]$.

Based on analysis of the cox1 DNA barcode region, sequences identified as C. obsoletus group into two major phylogenetic clades (Figs. 2, 3). All 67 sequences of $C$. obsoletus specimens obtained in the study conformed to one of these two clade (Clade 1) alongside sequences obtained during previous UK-based studies [25]. Clade 1 is thought to represent the classical morphological description of C. obsoletus [24] while the second clade includes specimens which have previously been associated 


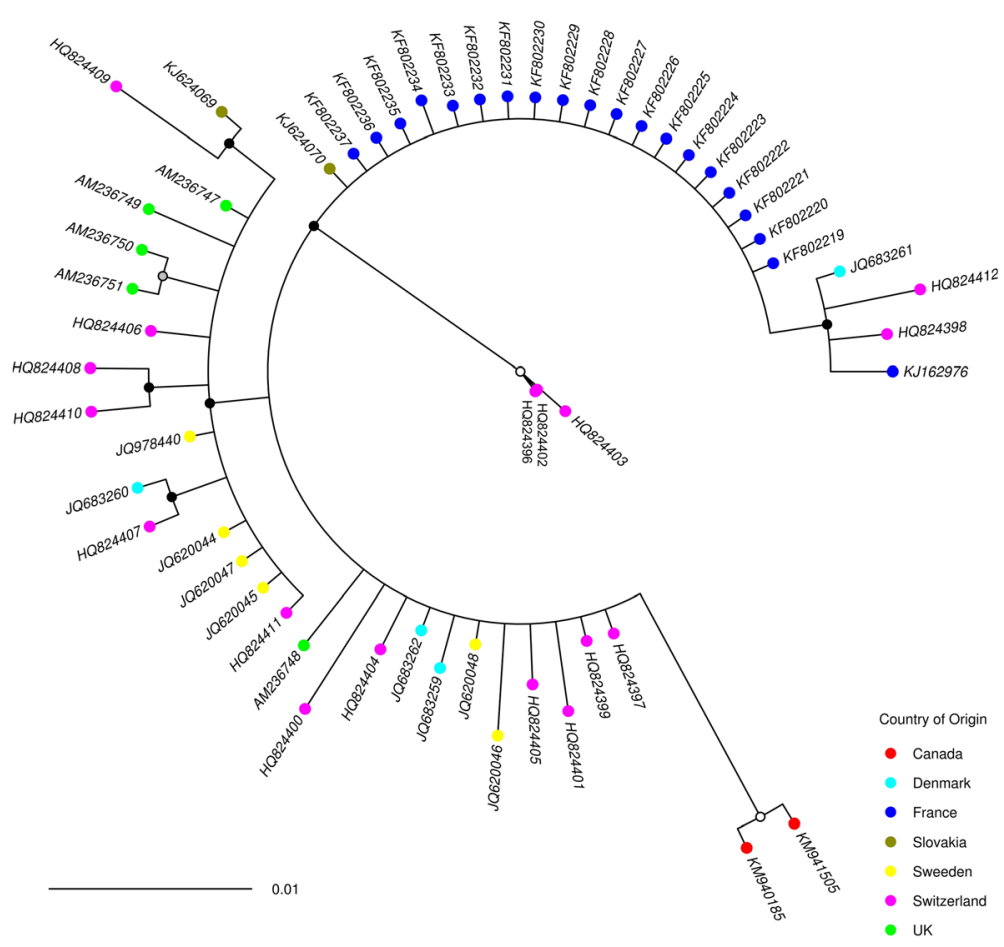

Fig. 6 Bayesian inference phylogenetic tree inferred from C. chiopterus cox1 DNA barcode sequences. Bayesian posterior probability node support values $\geq 0.95$ are shown as solid black circles at nodes, $0.75-0.94$ shown as black outline circles with grey fill at nodes and $<0.75$ shown as black outline circles with white fill at nodes. Geographical origin of specimens indicated by a coloured circle preceding the GenBank accession number for the sequence. Schmallenberg virus (SBV) vector competence indicates by colour of the GenBank accession number tip labels (red, positive; blue, negative; black, unknown). Clades shown represented in red in Fig. 2

with the 'dark' form of $C$. obsoletus in continental Europe [28]. Clade 2a (Figs. 2, 3) groups sequences of specimens which have been previously referenced as $C$. obsoletus O2 [59], while Clade 2b (Figs. 2, 3) contains a mixture of specimens which have been previously referenced as
C. obsoletus O1, O2 and O3 [65]. In contrast, C. scoticus, C. chiopterus and C. dewulfi were all strongly supported as monophyletic clades with relatively low intraspecific sequence differences (Figs. 2, 4, 5, 6, Table 4).

Table 4 Nucleotide sequence distances between UK Culicoides cox1 DNA barcodes. Uncorrected percent nucleotide sequence distances, mean with range shown in parentheses split by species including the proposed clades of $C$. obsoletus (see Fig. 2). Intraspecific distances are shown in bold along the diagonal, interspecific distances are shown below the diagonal. The number of specimens per species ( $n$ ) is shown in brackets followed by the number of specimens originating from this study; and the number originating from GenBank in parentheses

\begin{tabular}{|c|c|c|c|c|c|c|c|}
\hline & C. chiopterus & C. dewulfi & C. obsoletus & $\begin{array}{l}\text { C. obsoletus } \\
\text { Clade } 1\end{array}$ & $\begin{array}{l}\text { C. obsoletus } \\
\text { Clade } 2 \mathrm{a}\end{array}$ & $\begin{array}{l}\text { C. obsoletus } \\
\text { Clade } 2 \mathrm{~b}\end{array}$ & C. scoticus \\
\hline C. chiopterus $[56(0 ; 56)]$ & $0.8(0.0-3.3)$ & & & & & & \\
\hline C. dewulfi $[75(4 ; 71)]$ & $\begin{array}{l}22.5 \\
(20.5-23.5)\end{array}$ & $0.1(0.0-0.9)$ & & & & & \\
\hline C. obsoletus $[169(124 ; 145)]$ & $\begin{array}{l}14.9 \\
(13.2-18.3)\end{array}$ & $\begin{array}{l}19.3 \\
(17.5-22.8)\end{array}$ & $\begin{array}{l}4.1 \\
(0.0-12.3)\end{array}$ & & & & \\
\hline C. obsoletus Clade 1 [206 $(67 ; 139)]$ & $\begin{array}{l}14.6 \\
(13.2-16.4)\end{array}$ & $\begin{array}{l}18.8 \\
(17.5-20.6)\end{array}$ & & $0.9(0.0-4.4)$ & & & \\
\hline C. obsoletus Clade 2a [6 $(0 ; 6)]$ & $\begin{array}{l}16.2 \\
(14.1-18.3)\end{array}$ & $\begin{array}{l}21.0 \\
(19.4-22.8)\end{array}$ & & $9.4(7.6-11.7)$ & $1.7(0.0-8.1)$ & & \\
\hline C. obsoletus Clade 2b [57 (57; 0)] & $\begin{array}{l}14.7 \\
(13.8-15.5)\end{array}$ & $\begin{array}{l}20.2 \\
(19.6-21.0)\end{array}$ & & $11.1(10.2-12.3)$ & $8.6(7.9-9.3)$ & $0.6(0.2-0.9)$ & \\
\hline C. scoticus $[92(3 ; 89)]$ & $\begin{array}{l}14.0 \\
(12.0-15.8)\end{array}$ & $18.2(16.9-19.3)$ & $12.2(10.9-14.3)$ & $12.1(10.9-13.7)$ & $11.6(14.3)$ & $12.1(11.6-12.9)$ & $0.4(0.0-3.3)$ \\
\hline
\end{tabular}




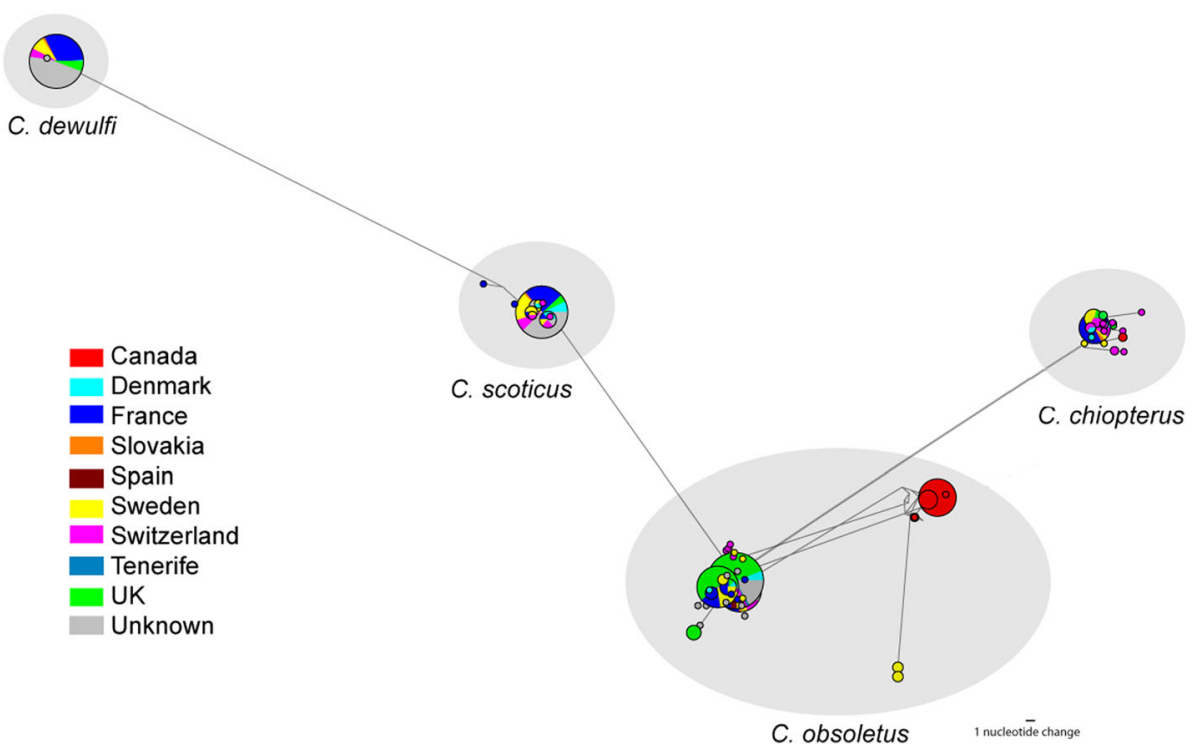

Fig. 7 Most parsimonious median-joining network $(\varepsilon=0)$ depicting phylogenetic relationships cox 1 haplotypes. The size of each circle is proportional to the corresponding haplotype frequency. Branch lengths are proportional to the number of nucleotide changes between haplotypes

Within the UK, further assessment of cryptic species prevalence and additional multi-locus studies are required across a wide-geographic area, both to assess the robustness of current PCR multiplex assays [25, 66] used to determine species in studies and to contribute to understanding relationships between phylogenetics and vector competence for arboviruses within the subgenus Avaritia. At a regional scale, studies are required that link both northwestern and northeastern European fauna and Nearctic species of the subgenus Avaritia. Several species in this group remain entirely uncharacterised using molecular markers, e.g. C. sanguisuga (Coquillett). Such data will then make decisions whether the observed sequence diversity represents novel species or potentially species that require resurrection from synonymy permissible, e.g. C. dobyi Callot \& Kremer [67]. To resolve these issues it is particularly important that specimens are collected from the species type-locality in order to confirm that subsequent specimens are in fact conspecific (see Harrup et al. [68] for review).

Inaccurate species identification can have significant impacts on epidemiological investigations and control attempts when species have divergent vector competences and/or habitat and host preferences. Examination of the relative relationship between species within the subgenus Avaritia and confirmation of the monophyletic status of the subgenus, coupled with further arbovirus vector competence experiments will allow investigation of whether arbovirus vector competence is an ancestral character in the Obsoletus complex as previously proposed for the Imicola complex [69] or whether vector competence has evolved multiple times within this group.

\section{Conclusions}

Methods described in this study provide the means to blood-feed Palaearctic Culicoides for vector competence studies and colonisation attempts. Susceptibility to SBV infection was $7.3 \%$ for membrane-fed members of the subgenus Avaritia and $1.1 \%$ for pledglet-fed. Both $C$. obsoletus and C. scoticus were confirmed as being susceptible to infection with SBV, with potential evidence of cryptic species within UK Obsoletus complex specimens; however the implications of cryptic diversity in the Obsoletus complex on arbovirus transmission remains unknown. This is important as these species are the most abundant Culicoides biting midges on farms across northwestern Europe and arboviruses transmitted by them continue to emerge in this region.

\section{Additional files}

Additional file 1: Table S1. GenBank sequences used in the genetic analyses of Obsoletus complex of Culicoides. Includes references listed for GenBank sequences. (DOCX $79 \mathrm{~kb}$ )

Additional file 2: Table S2. Blood-feeding data for UK Culicoides exposed to membrane types. Number of Culicoides of each physiological state recorded following exposure to blood-feeding apparatus. (XLSX 21 kb)

\section{Abbreviations}

AIC: Akaike information criterion; BIC: Bayesian information criterion; BIN: Barcode index number; BTV: Bluetongue virus; DNA: Deoxyribonucleic acid; HKY+G: Hasegawa-Kishino-Yano with gamma-distribution rates; cox1: Mitochondrial cytochrome c oxidase subunit 1 gene;

OVI: Onderstepoort Veterinary Institute; RDF: Roehl haplotype data files; RH: Relative humidity; RNA: Ribonucleic acid; RT-qPCR: Quantitative reverse transcription polymerase chain reaction; SBV: Schmallenberg virus 


\section{Acknowledgements}

We acknowledge Nonito Pages, Maria Goffredo, Thomas Balenghien and Claire Garros for useful discussions on the subject of the manuscript. We also acknowledge provision of the SBV strain used in experiments by IZS Teramo (Federica Monaco) from an isolate originally made available by the Institute of Diagnostic Virology, Friedrich-Loeffler-Institut, Riems, Germany (Martin Beer/Bernd Hoffmann).

\section{Funding}

This study was funded by EU grant FP7-261504 EDENext (http://www.edenext.eu). SC was additionally funded by BBSRC grant BBS/E///00001701.

\section{Availability of data and materials}

All data generated or analysed during this study are included in this published article and its additional files, with the exception of barcode sequence data which are listed by GenBank accession number. DNA sequences including electropherograms have been made publically available via the Barcode of Life Data System (BOLD) as data set DS-CUSBV (dx.doi.org/10.5883/DS-CUSBV). DNA sequences are also available in the GenBank database under accession numbers KT186808-KT186881.

\section{Authors' contributions}

JB performed studies, edited and approved submission. LH carried out phylogenetic analysis, wrote and approved submission. RS processed samples, edited and approved submission. EV supervised studies, contributed to experimental design and edited and approved submission. SG carried out statistical analyses and edited and approved submission. KB carried out DNA sequencing and edited and approved submission. SC produced the experimental design, supervised the study and wrote and approved the submission. All authors read and approved the final manuscript.

\section{Ethics approval and consent to participate}

Chicks used in the trials were purchased dead and frozen from a local pet shop and blood was sourced from a commercial supplier (TCS Biosciences). No technique used during the trial required ethical approval.

\section{Consent for publication}

Not applicable.

\section{Competing interests}

The authors declare that they have no competing interests.

\section{Publisher's Note}

Springer Nature remains neutral with regard to jurisdictional claims in published maps and institutional affiliations.

\section{Author details}

'Vector-borne Viral Disease Programme, The Pirbright Institute, Pirbright, Surrey, UK. ${ }^{2}$ National Centre for Vector Entomology, Institute of Parasitology, University of Zürich, Winterthurerstr. 266a, 8057 Zürich, Switzerland.

\section{Received: 22 April 2017 Accepted: 16 January 2018}

\section{Published online: 27 February 2018}

\section{References}

1. Hoffmann B, Scheuch M, Höper D, Jungblut R, Holsteg M, Schirrmeier $H$, et al. Novel Orthobunyavirus in cattle, Europe 2011. Emerg Infect Dis. 2012;18: 469-72.

2. Doceul V, Lara E, Sailleau C, Belbis G, Richardson J, Breard E, et al. Epidemiology, molecular virology and diagnostics of Schmallenberg virus, an emerging Orthobunyavirus in Europe. Vet Res. 2013:44:31.

3. Purse BV, Carpenter S, Venter GJ, Bellis G, Mullens BA. Bionomics of temperate and tropical Culicoides midges: Knowledge gaps and consequences for transmission of Culicoides-borne viruses. Annu Rev Entomol. 2014;60:373-93.

4. Carpenter S, Groschup MH, Garros C, Felippe-Bauer ML, Purse BV. Culicoides biting midges, arboviruses and public health in Europe. Antiviral Res. 2013; 100(1):102-13

5. King B, O'Shea Brown T, Tarlinton R, Daly JM. Seroprevalence of Schmallenberg virus in the United Kingdom and the Republic of Ireland: 2011-2013. Vet Microbiol. 2015;180(1-2):36-40.
6. Barrett D, More SJ, O'Neill R, Bradshaw B, Casey M, Keane M, et al. Prevalence and distribution of exposure to Schmallenberg virus in Irish cattle during October 2012 to November 2013. BMC Vet Res. 2015; 11(1):267.

7. Chenais E, Stahl K, Frossling J, Blomqvist G, Naslund K, Svensson L, et al. Schmallenberg virus beyond latitude 65 degrees N. Transbound Emerg Dis. 2015;62(5):e11-8.

8. Meroc E, Poskin A, Van Loo H, Van Driessche E, Czaplicki G, Quinet C, et al. Follow-up of the Schmallenberg virus seroprevalence in Belgian cattle. Transbound Emerg Dis. 2015;62(5):e80-4.

9. Wernike K, Holsteg M, Sasserath M, Beer M. Schmallenberg virus antibody development and decline in a naturally infected dairy cattle herd in Germany, 2011-2014. Vet Microbiol. 2015;181(3-4):294-7.

10. Surveillance SBV Congenital - Saison 2015/2016 Bilan au 18 julliet 2016 [http://plateforme-esa.fr/sites/default/files/ Surveillance\%20SBV\%20congénital_2015-2016_Traitement\%204.pdf] Accessed on 19/12/17.

11. VMD authorises SBV vaccine for use in the UK. Vet Record. 2013;172(21): 543-543.

12. Carpenter S, Wilson A, Mellor PS. Culicoides and the emergence of bluetongue virus in northern Europe. Trends Microbiol. 2009;17(4):172-8.

13. Yanase T, Kato T, Aizawa M, Shuto Y, Shirafuji H, Yamakawa M, Tsuda T. Genetic reassortment between Sathuperi and Shamonda viruses of the genus Orthobunyavirus in nature: implications for their genetic relationship to Schmallenberg virus. Arch Virol. 2012;157(8):1611-6.

14. Balenghien T, Pages N, Goffredo M, Carpenter S, Augot D, Jacquier E, et al. The emergence of Schmallenberg virus across Culicoides communities and ecosystems in Europe. Prev Vet Med. 2014;116(4):360-9.

15. Elbers AR, Meiswinkel R, van Weezep E, van Oldruitenborgh-Oosterbaan MM, Kooi EA. Schmallenberg virus in Culicoides spp. biting midges, the Netherlands, 2011. Emerg Infect Dis. 2013;19(1):106-9.

16. Elbers AR, Meiswinkel $R$, van Weezep E, Kooi EA, van der Poel WH. Schmallenberg virus in Culicoides biting midges in the Netherlands in 2012. Transbound Emerg Dis. 2015;62(3):339-42.

17. De Regge N, Deblauwe I, De Deken R, Vantieghem P, Madder M, Geysen D, et al. Detection of Schmallenberg virus in different Culicoides spp. by realtime RT-PCR. Transbound Emerg Dis. 2012;59(6):471-5.

18. De Regge N, De Deken R, Fassotte C, Losson B, Deblauwe I, Madder M, et al. Culicoides monitoring in Belgium in 2011: analysis of spatiotemporal abundance, species diversity and Schmallenberg virus detection. Med Veterinary Entomol. 2015;29(3):263-75.

19. Wernike K, Jost H, Becker N, Schmidt-Chanasit J, Beer M. Lack of evidence for the presence of Schmallenberg virus in mosquitoes in Germany, 2011. Parasit Vectors. 2014;7:402.

20. Veronesi E, Henstock M, Gubbins S, Batten C, Manley R, Barber J, et al. Implicating Culicoides biting midges as vectors of Schmallenberg virus using semi-quantitative RT-PCR. PLoS One. 2013;8(3):e57747.

21. Manley R, Harrup LE, Veronesi E, Stubbins F, Stoner J, Gubbins S, et al. Testing of UK populations of Culex pipiens L. for Schmallenberg virus vector competence and their colonization. PLoS One. 2015;10(8):e0134453.

22. Meiswinkel R, Scolamacchia F, Dik M, Mudde J, Dijkstra E, Van Der Ven IJ, Elbers AR. The Mondrian matrix: Culicoides biting midge abundance and seasonal incidence during the 2006-2008 epidemic of bluetongue in the Netherlands. Med Vet Entomol. 2014;28(1):10-20.

23. Searle KR, Barber J, Stubbins F, Labuschagne K, Carpenter S, Butler A, et al. Environmental drivers of Culicoides phenology: How important is speciesspecific variation when determining disease policy? PLoS One. 2014;9(11): e111876.

24. Campbell JA, Pelham-Clinton EC. Taxonomic review of the British species of Culicoides Latreille (Diptera, Ceratopogonidae). Proc Roy Entomol Soc Lon (B). 1960;67:181-302.

25. Nolan DV, Carpenter S, Barber J, Mellor PS, Dallas JF, Mordue Luntz AJ, Piertney SB. Rapid diagnostic PCR assays for members of the Culicoides obsoletus and Culicoides pulicaris species complexes, implicated vectors of bluetongue virus in Europe. Vet Microbiol. 2007;124(1-2):82-94.

26. Schwenkenbecher JM, Mordue AJ, Piertney SB. Phylogenetic analysis indicates that Culicoides dewulfi should not be considered part of the Culicoides obsoletus complex. Bull Entomol Res. 2009:99(4):371-5.

27. Kirkeby C, Dominiak P. Culicoides (Avaritia) gornostaevae Mirzaeva, 1984 (Diptera: Ceratopogonidae) - a possible vector species of the Obsoletus group new to the European fauna. Parasit Vectors. 2014;7:445. 
28. Meiswinkel R, De Bree F, Bossers-De Vries R, Elbers AR. An unrecognized species of the Culicoides obsoletus complex feeding on livestock in the Netherlands. Vet Parasitol. 2015;207(3-4, 324):-328.

29. Pettersson E, Bensch S, Ander M, Chirico J, Sigvald R, Ignell R. Molecular identification of bloodmeals and species composition in Culicoides biting midges. Med Vet Entomol. 2013;27(1):104-12.

30. Carpenter S, Lunt HL, Arav D, Venter GJ, Mellor PS. Oral susceptibility to bluetongue virus of Culicoides (Diptera: Ceratopogonidae) from the United Kingdom. J Med Entomol. 2006;43(1):73-8.

31. Venter GJ, Paweska JT, Lunt H, Mellor PS, Carpenter S. An alternative method of blood-feeding Culicoides imicola and other haematophagous Culicoides species for vector competence studies. Vet Parasitol. 2005; 131(3-4):331-5.

32. Nayduch D, Cohnstaedt LW, Saski C, Lawson D, Kersey P, Fife M, Carpenter S. Studying Culicoides vectors of BTV in the post-genomic era: Resources, bottlenecks to progress and future directions. Virus Res. 2014;182:43-9.

33. Venter GJ, Paweska JT, van Dijk AA, Mellor PS, Tabachnick WJ. Vector competence of Culicoides bolitinos and C. imicola for South African bluetongue virus serotypes 1, 3 and 4. Med Vet Entomol. 1998;12(4):378-85.

34. Dyce AL. The recognition of nulliparous and parous Culicoides (Diptera: (eratopogonidae) without dissection. J Aust Entomol Soc. 1969:8:11-5.

35. Harrup LE, Purse BP, Golding N, Mellor PS, Carpenter S. Larval development and emergence sites of farm-associated Culicoides (Diptera: Ceratopogonidae) in the United Kingdom. Med Vet Entomol. 2013;27(4):441-9.

36. Hebert PD, Cywinska A, Ball SL, deWaard JR. Biological identifications through DNA barcodes. Proc Biol Sci. 2003;270(1512):313-21.

37. Folmer $\mathrm{O}$, Black M, Hoeh W, Lutz R, Vrijenhoek R. DNA primers for amplification of mitochondrial cytochrome c oxidase subunit I from diverse metazoan invertebrates. Mol Mar Biol Biotech. 1994;3:294-9.

38. Hebert PDN, Penton EH, Burns JM, Janzen DH, Hallwach W. Ten species in one: DNA barcoding reveals cryptic species in the Neotropical skipper butterfly Astraptes fulgerator. Proc Nat Acad Sci USA. 2004;101:14812-7.

39. Ratnasingham S, Hebert PDN. BOLD: The Barcode of Life Data System. Mol Ecol Notes. 2007;7:355-64. www.barcodinglife.org.

40. Madden T. The BLAST Sequence Analysis Tool, avaliable at http://www.ncbi.nlm. nih.gov/books/NBK21097. In: The NCBI Handbook. Edited by McEntyre J, Ostell J. Bethesda MD, USA: National Center for Biotechnology Information; 2003.

41. Edgar RC. MUSCLE: multiple sequence alignment with high accuracy and high throughput. Nucleic Acids Res. 2004;32(5):1792-7.

42. Penn O, Privman E, Landan G, Graur D, Pupko T. An alignment confidence score capturing robustness to guide-tree uncertainty. Mol Biol Evol. 2010; 27(8):1759-67.

43. Darriba D, Taboada GL, Doallo R, Posada D. jModelTest 2: more models, new heuristics and parallel computing. Nat Methods. 2012;9(8):772.

44. Guindon S, Gascuel O. A simple, fast and accurate method to estimate large phylogenies by maximum-likelihood. Systematic Biol. 2003;52:696-704.

45. Huelsenbeck JP, Ronquist F. MRBAYES: Bayesian inference of phylogeny. Bioinformatics. 2001;17:754-5.

46. Ronquist F, Huelsenbeck JP. MRBAYES 3: Bayesian phylogenetic inference under mixed models. Bioinformatics. 2003;19:1572-4.

47. Hasegawa M, Kishino H, Yano T. Dating of the human-ape splitting by a molecular clock of mitochondrial DNA. J Mol Evol. 1985;22(2):160-74.

48. Harrup LE, Laban S, Purse BV, Reddy YK, Reddy YN, Byregowda SM, et al. DNA barcoding and surveillance sampling strategies for Culicoides biting midges (Diptera: Ceratopogonidae) in southern India. Parasit Vectors. 2016;9:461.

49. Ratnasingham S, Hebert PDN. A DNA-based registry for all animal species: The Barcode Index Number (BIN) system. PLoS One. 2013;8(7):e66213.

50. Nylander JAA, Wilgenbusch JC, Warren DL, Swofford DL. AWTY: A system for graphical exploration of MCMC convergence in Bayesian phylogenetics. Bioinformatics. 2008;24(4):581-3.

51. Paradis E, Claude J, Strimmer K. APE: analyses of phylogenetics and evolution in R language. Bioinformatics. 2004;20:289-90.

52. Revell LJ. phytools: An R package for phylogenetic comparative biology (and other things). Meth Ecol Evol. 2012;3:217-23.

53. R Development Core Team. R: A language and environment for statistical computing. R Foundation for Statistical Computing, Vienna, Austria. ISBN 3900051-07-0, http://www.R-project.org . 2.9.1 edn2014.

54. Librado P, Rozas J. DnaSP v5: A software for comprehensive analysis of DNA polymorphism data. Bioinformatics. 2009;25:1451-2.

55. Fluxus-Engineering. Network version 4.6.1.2, avaliable at: http://www.fluxusengineering.com/sharenet.htm. 2014.
56. Bandelt H-J, Forster $P$, Röhl A. Median-joining networks for inferring intraspecific phylogenies. Mol Biol Evol. 1999;16:37-48.

57. Polzin T, Daneschmand SV. On Steiner trees and minimum spanning trees in hypergraphs. Oper Res Lett. 2003:31:12-20.

58. Brown SD, Collins RA, Boyer S, Lefort MC, Malumbres-Olarte J, Vink CJ, Cruickshank RH. Spider: an R package for the analysis of species identity and evolution, with particular reference to DNA barcoding. Mol Ecol Resour. 2012;12(3):562-5.

59. Wenk CE, Kaufmann C, Schaffner F, Mathis A. Molecular characterization of Swiss Ceratopogonidae (Diptera) and evaluation of real-time PCR assays for the identification of Culicoides biting midges. Vet Parasitol. 2012;184(2-4):258-66.

60. Jennings DM, Mellor PS. The vector potential of British Culicoides species for bluetongue virus. Vet Microbiol. 1988;17(1):1-10.

61. Blackwell A, Mellor PS, Mordue W. Laboratory feeding of Culicoides impunctatus (Diptera: Ceratopogonidae) through natural and artificial membranes. Med Vet Entomol. 1994;31(2):302-5.

62. Blackwell A, Mellor PS, Mordue W. Methods for enhancing the blood feeding response of field-collected Culicoides impunctatus (Diptera: Ceratopogonidae). J Med Entomol. 1996;33(3):504-6.

63. Gubbins S, Richardson J, Baylis M, Wilson AJ, Abrahantes JC. Modelling the continental-scale spread of Schmallenberg virus in Europe: approaches and challenges. Prev Vet Med. 2014;116(4):404-11.

64. Gubbins S, Turner J, Baylis M, van der Stede Y, van Schaik G, Abrahantes JC, Wilson AJ. Inferences about the transmission of Schmallenberg virus within and between farms. Prev Vet Med. 2014;116(4):380-90.

65. Ander M, Troell K, Chirico J. Barcoding of biting midges in the genus Culicoides: a tool for species determination. Med Vet Entomol. 2013;27(3):323-31.

66. Mathieu B, Delécolle JC, Garros C, Balenghien T, Setier-Rio ML, Candolfi E, Cêtre-Sossah C. Simultaneous quantification of the relative abundance of species complex members: application to Culicoides obsoletus and Culicoides scoticus (Diptera: Ceratopogonidae), potential vectors of bluetongue virus. Vet Parasitol. 2011;182(2-4):297-306.

67. Gomulski LM, Meiswinkel R, Delécolle JC, Goffredo M, Gasperi G. Phylogenetic relationships of the sub-genus Avaritia Fox, 1995 including Culicoides obsoletus (Diptera, Ceratopogonidae) in Italy based on internal transcribed spacer 2 ribosomal DNA sequences.. 2005;10:1-13.

68. Harrup L, Bellis GA, Balenghien T, Garros C. Culicoides Latreille (Diptera: Ceratopogonidae) taxonomy: Current challenges and future directions. Infect Genet Evol. 2015;30:249-66.

69. Linton YM, Mordue AJ, Cruickshank RH, Meiswinkel R, Mellor PS, Dallas JF. Phylogenetic analysis of the mitochondrial cytochrome oxidase subunit I gene of five species of the Culicoides imicola species complex. Med Vet Entomol. 2002;16:139-46.

\section{Submit your next manuscript to BioMed Central and we will help you at every step:}

- We accept pre-submission inquiries

- Our selector tool helps you to find the most relevant journal

- We provide round the clock customer support

- Convenient online submission

- Thorough peer review

- Inclusion in PubMed and all major indexing services

- Maximum visibility for your research

Submit your manuscript at www.biomedcentral.com/submit
Biomed Central 